\title{
ƯNG DỤNG VIẼ̃N THÁM VÀ GIS THÀNH LẬP BẢN ĐỒ NGUY CƠ TRƯợT LỞ ĐẤT TẠI TỈNH BẮC KẠN
}

\author{
ThS. NGUYẼ̃N ĐìNH TÀl, PGS. TS. NGUYẼ̃N NGOC THACH
}

Trường Đại học Khoa học Tự nhiên, Đại học Quốc gia Hà Nội

\section{Tóm tắt}

Trong nghiên cứu này, chúng tôi đề cập đến việc ứng dụng tư liệu ảnh viễn thám độ phân giải cao kết hợp với khảo sát thực địa để thành lập bản đồ hiện trạng trượt lở đất. Kỹ thuật giải đoán bằng mắt tỏ ra phù hợp cho việc phát hiện vị trí các vết trượt lở đất dựa trên sụ̣ khác biệt về độ xám của ảnh, đặc biệt các dấu hiệu về sự thay đổi độ cao địa hình liên quan đến trượt lở cũng dễ dàng phát hiện nhờ chồng phủ ảnh vệ tinh lên mô hình số độ cao. Bản đồ nguy cơ trượt lở đất được thành lập bằng mô hình giá trị thông tin cũng được đề cập trong nghiên cứu này. Cuối cùng, nghiên cứu đã kiểm chứng bằng cách tính diện tích dưới đường cong (AUC-Area Under Curve) nhằm đánh giá độ chính xác của mô hình nghiên cứu.

\section{Mở đầu}

Bắc Kạn là một tỉnh có địa hình đồi núi tương đối cao nằm trong vùng Đông Bắc Việt Nam. Hàng năm, hiện tượng trượt lở diễn ra khá phổ biến, phân bố trên diện rộng gây hậu quả nghiêm trọng cho người và tài sản tại các khu vực xảy ra trượt lở. Để giảm thiểu những thiệt hại do tai biến trượt lở đất thì việc cảnh báo nguy cơ xảy ra trượt lở đối với từng khu vực là cần thiết. Hiện nay, với sự trợ giúp của viễn thám và hệ thông tin địa lý (GIS), nhiều phương pháp để thành lập bản đồ nguy cơ trượt lở đã được áp dụng như phương pháp trọng số bằng chứng, phương pháp hồi quy logistic, hồi quy tuyến tính. Mối quan hệ định lượng giữa trượt lở đất và các nhân tố ảnh hưởng trực tiếp đến quá trình trượt lở được xây dựng dựa vào mô hình giá trị thông tin (Information Value) được tác giả đề cập trong nghiên cứu này. Các nhân tố gồm: độ dốc, lượng mưa trung bình năm, địa mạo, lớp phủ thực vật, thạch học, độ lệch hướng cắm của đá với địa hình, vỏ phong hóa, mật độ lineament, mật độ chia chắt ngang, mật độ chia cắt sâu,

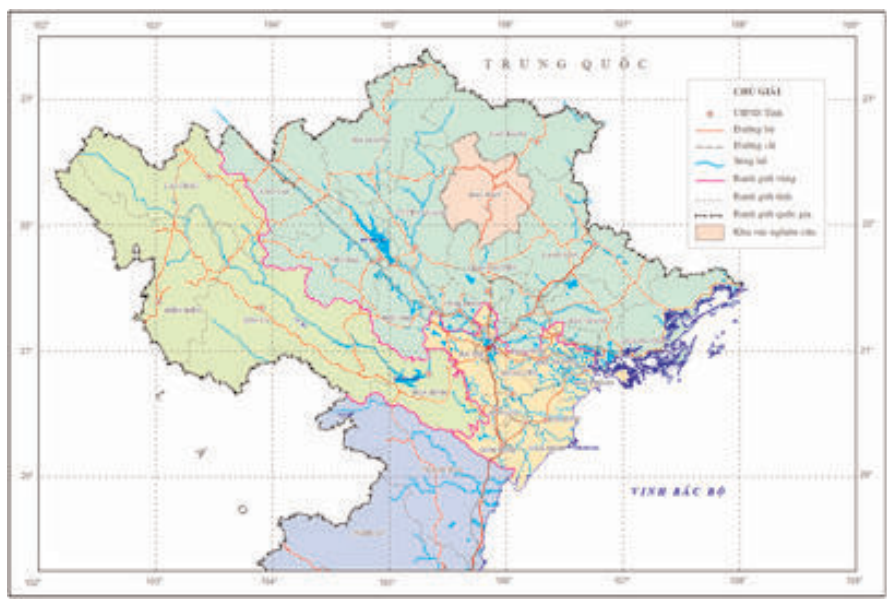

Hình 1: Vị trí khu vực nghiên cứu 
khoảng cách tới đường giao thông. Kết quả đã thành lập bản đồ nguy cơ trượt lở với 5 mức: rất thấp, thấp, trung bình, cao, rất cao.

\section{Phương pháp thành lập bản đồ hiện trạng trượt lở}

Bản đồ hiện trạng trượt lở được coi là nhân tố đầu vào quan trọng không thể thiếu trong các mô hình phân tích nguy cơ trượt lở dựa vào phương pháp thống kê. Vị trí các điểm trượt lở có thể đo vẽ bằng khảo sát thực địa hoặc giải đoán từ ảnh vệ tinh. Tuy nhiên đối với các khu vực có quy mô nghiên cứu tương đối rộng lớn và địa hình đồi núi, giao thông chưa thuận lợi như Bắc Kạn thì việc thu thập thông tin trượt lở đất bằng khảo sát thực địa là rất tốn thời gian và chi phí. Trong khi đó, tư liệu viễn thám có thể cung cấp những thông tin quan trọng về vị trí trượt lở đất với hiệu quả kinh tế cao. Trong nghiên cứu này, vị trí trượt lở đất được giải đoán bằng mắt trên cơ sở sự khác nhau khác nhau giữa các tông ảnh; sự thay đổi của độ cao địa hình thông qua việc chồng phủ các ảnh vệ tinh lên mô hình số độ cao (DEM). Với tư liệu viễn thám đa thời gian, có độ phân giải cao và kết quả khảo sát trong hai chuyển thực địa năm 2010 và

Bảng 1: Tư liệu ảnh vệ tinh sử dụng trong nghiên cứu

\begin{tabular}{|c|c|c|c|}
\hline Ảnh & Sensor & Độ phân giải & Ngày chụp \\
\hline GeoEye-1 & Pancromatic & $0,5 \mathrm{~m}$ & $19 / 04 / 2009$ \\
\hline GeoEye-1 & Pancromatic & $0,5 \mathrm{~m}$ & $10 / 11 / 2010$ \\
\hline GeoEye-1 & Pancromatic & $0,5 \mathrm{~m}$ & $30 / 08 / 2011$ \\
\hline GeoEye-1 & Multi-color & $2 \mathrm{~m}$ & $18 / 10 / 2011$ \\
\hline SPOT 4 & Multi-color & $10 \mathrm{~m}$ & $11 / 2008$ \\
\hline SPOT 5 & Multi-color & $2,5 \mathrm{~m}$ & $10 / 03 / 2011$ \\
\hline
\end{tabular}

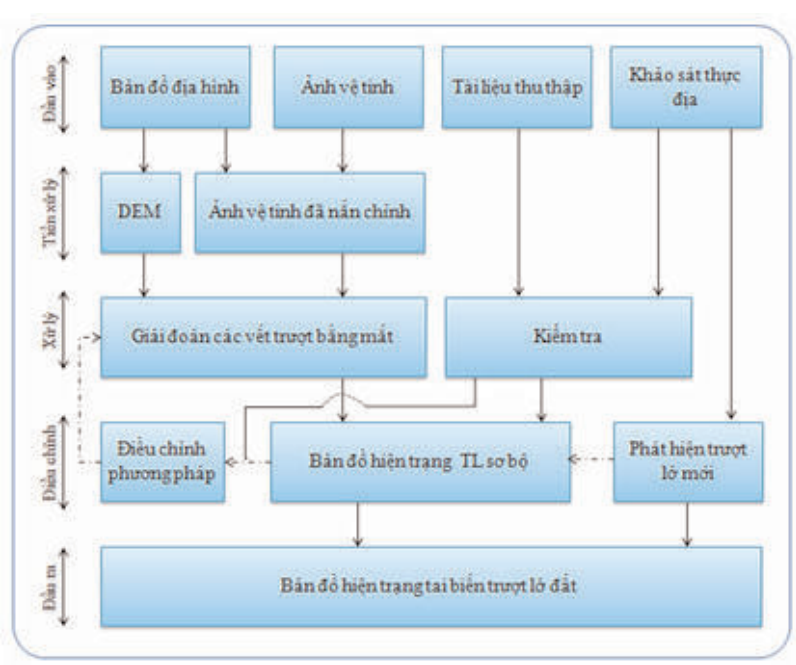

Hình 2: Quy trình thành lập bản đồ hiện trạng trượt lở
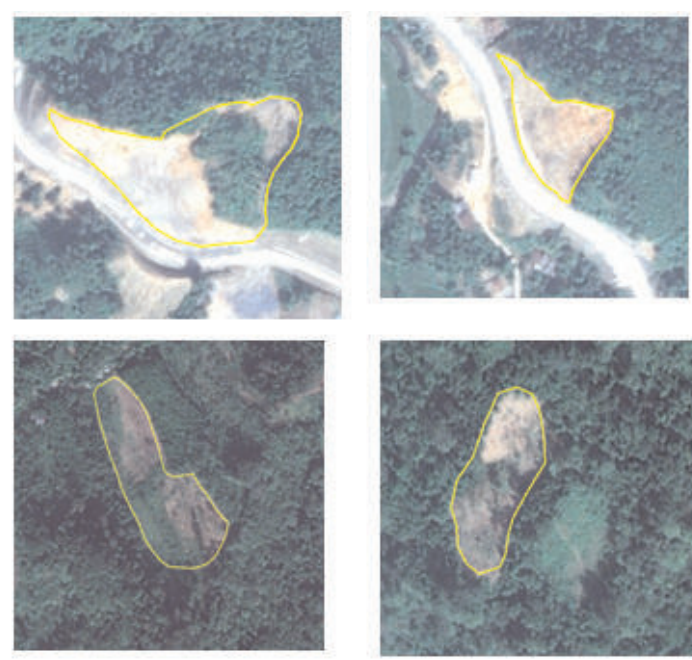

Hình 3: Vị trí vết trượt trên ảnh SPOT4 


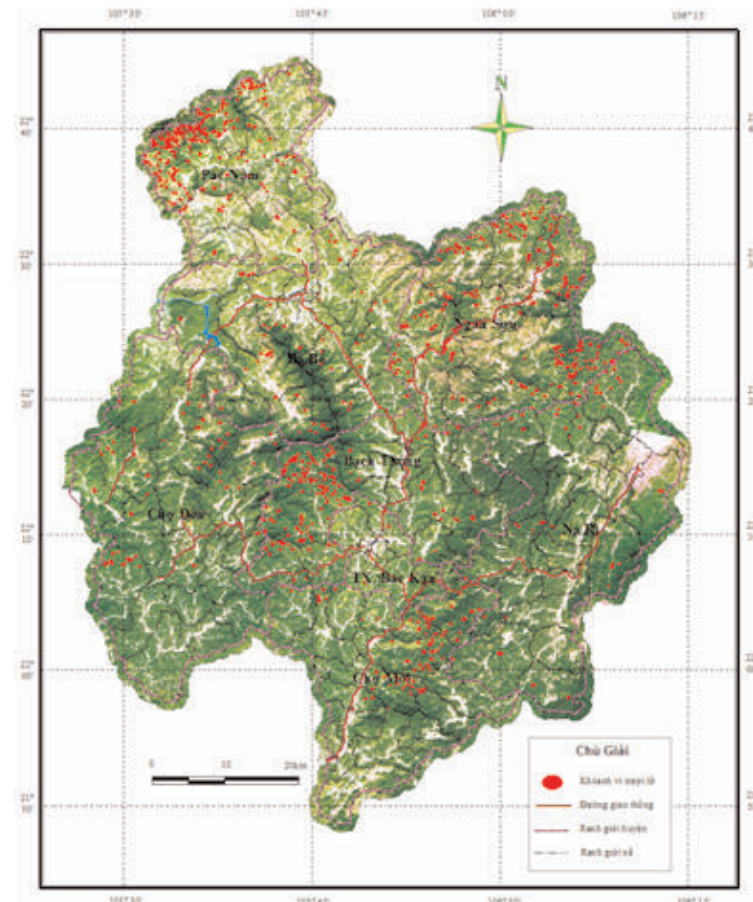

Hình 4: Hiện trạng trượt lở tỉnh Bắc Kạn

2011, nhìn chung kết quả giải đoán đã phản ánh một cách chi tiết về hiện trạng trượt lở đất ở đây.

Bản đồ phân bố trượt lở cho thấy trượt lở xuất hiện ở nhiều khu vực khác nhau, trong đó tập trung nhiều ở dọc theo các tuyến đường giao thông chính (QL 3, các tỉnh lộ $258,254,279)$ và ở các huyện Pắc Nậm, Ngân Sơn. (Xem hình 4, hình 5)

\section{Các yếu tố gây trượt}

Hiện tượng trượt lở đất xuất phát từ sự biến đổi của vật liệu đang trong trạng thái ổn định chuyển sang không ổn định, phức tạp cả về nguyên nhân gây trượt, cơ chế tác động, kiểu dịch chuyển, loại vật liệu.v.v... Nguyên nhân của trượt lở đất đã được đề cập đến trong nhiều nghiên cứu (Wieczorek, 1996). Theo Schuster, có it nhất khoảng 20 thông số làm cho trượt lở đất xảy ra và các nhà nghiên cứu có thể chọn các thông số cần thiết mà họ cần cho các nghiên cứu của mình tùy theo quy mô,

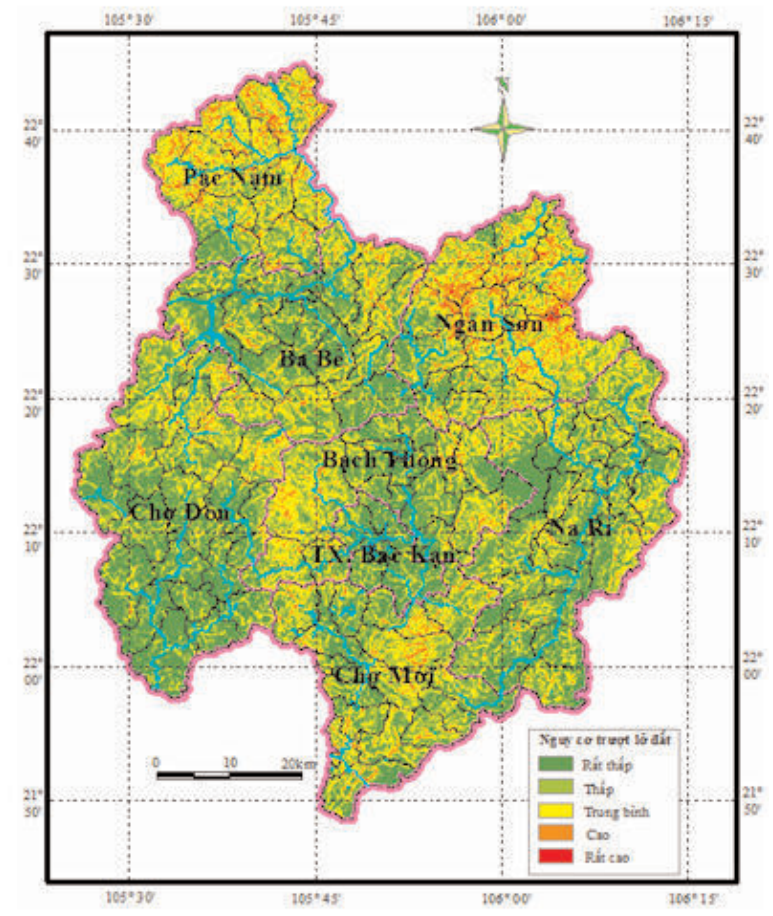

Hình 5: Nguy cơ trượt lở tỉnh Bắc Kạn

diện tích khu vực (Schuster, 1996). Mặt khác, Ayalew đã nhận xét là độ chính xác của bản đồ nguy cơ tăng lên khi tất cả các thông số khống chế sự kiện được sử dụng trong quá trình phân tích (Ayalew và nnk., 2004). Tuy nhiên việc có được đầy đủ, chi tiết dữ liệu của các thông số thường không dễ dàng gì, và khi tiến hành phân tích trên GIS thường rất phức tạp. Trong các nguyên nhân này, một số có thể được nhận biết với các công cụ khảo sát thông thường ngoài hiện trường hoặc đòi hỏi sự vào cuộc của các ngành khác như vật lý địa cầu, khí tượng thủy văn... Sự thay đổi về mặt hình thái học địa mạo theo thời gian có thể nhận biết kết hợp qua phân tích thực địa, bản đồ và ảnh vệ tinh qua các thời kỳ. Những thay đổi bên trong vật liệu và đặc tính khối theo thời gian được suy luận từ quá trình đo đạc, quan trắc sự biến đồi dần dần các tính chất của khối theo thời gian và khoảng cách di chuyển.

Với nghiên cứu này, 11 thông số đã được 
Bảng 2: Các lớp thông tin dùng đánh giá nguy cơ trượt lở đất

\begin{tabular}{|c|l|l|c|}
\hline TT & \multicolumn{1}{|c|}{ Các yếu tố lựa chọn } & \multicolumn{1}{c|}{ Dứ liệu gốc } & Tỷ lệ \\
\hline 1 & Độ dốc & Bản đồ địa hình & $1: 50.000$ \\
\hline 2 & Thành phần thạch học & Bản đồ địa chất khoáng sản & $1: 200.000$ \\
\hline 3 & Lớp phủ thực vật & Bản đồ rừng, ảnh vệ tinh SPOT & $1: 50.000,10 \mathrm{~m} \times 10 \mathrm{~m}$ \\
\hline 4 & Vỏ phong hoá & Bản đồ vỏ phong hoá & $1: 100.000$ \\
\hline 5 & Địa mạo & Bản đồ địa mạo & $1: 100.000$ \\
\hline 6 & Lượng mưa & Số liệucác trạm đo mưa & $1: 50.000$ \\
\hline 7 & Khoảng cách tới đường giao thông & Bản đồ địa hình & $1: 50.000$ \\
\hline 8 & Độ lệch hướng cắm & $\begin{array}{l}\text { Bản đồ địa chất \& khoáng sản } \\
\text { kêt hợp với bản đồ địa hình }\end{array}$ & $1: 50.000$ \\
\hline 9 & Mật độ lineament & Ảnh vệ tinh kết hợp DEM & $1: 50.000$ \\
\hline 10 & Chia cắt sâu & Bản đồ địa hình & $1: 50.000$ \\
\hline 11 & Chia cắt ngang & Bản đồ địa hình & $1: 50.000$ \\
\hline
\end{tabular}

lựa chọn cho mô hình đánh giá nguy cơ trượt lở đất gồm: 1) độ dốc địa hình; 2) thạch học; 3) Thảm thực vật; 4) Vỏ phong hóa; 5) Địa mạo; 6) Lượng mưa; 7) Khoảng cách tới đường giao thông; 8) độ lệch giữa hướng cắm của đá và hướng đổ của địa hình; 9) mật độ lineament; 10) chia cắt sâu; 11) chia cắt ngang. (Xem bảng 2)

\section{Mô hình giá trị thông tín}

Phân tích thống kê đơn biến thuộc nhóm các phương pháp định lượng (định lượng tầm quan trọng tương đối của các yếu tố gây trượt khác nhau). Đây là phương pháp có khả năng giảm thiểu tính chủ quan trong quá trình gán trọng số bằng cách thống kê (so sánh) sự phân bố không gian của các vết trượt có liên quan đến các yếu tố gây trượt khác nhau trong quá khứ (Aleotti và Chowdhury, 1999). Nói cách khác là phương pháp so sánh sự phân bố không gian của các vết trượt có liên quan đến các yếu tố gây trượt khác nhau, mỗi lớp dữ liệu chuyên đề đơn lẻ (yếu tố gây trượt) được so sánh với bản đồ hiện trạng phân bố trượt lở. Trong kỹ thuật phân tích thông kê đơn biến, ảnh hưởng của từng yếu tố đến trượt lở được coi là riêng biệt và giả định các yếu tố này thực hiện độc lập với nhau (Dahal và nnk., 2008). Kỹ thuật này được đề xuất để xác định mật độ trượt lở ở các lớp tham số khác nhau, liên quan đến mật độ trượt lở đất trên toàn bộ khu vực nghiên cứu. Có nhiều mô hình thuộc nhóm phân tích thống kê đơn biến (Bivariate Statistical AnalysisBSA) để tính thứ hạng cho các lớp dựa trên mật độ trượt lở như mô hình trọng số bằng chứng, mô hình hồi quy logistic, mô hình giá trị thông tin... Trong nghiên cứu này, mô hình giá trị thông tin (Yin và Yan, 1988) đã được lựa chọn để áp dụng tính toán nguy cơ trượt lở cho khu vực nghiên cứu. Theo đó, thứ hạng của các lớp được tính dựa trên công thức sau:

$$
W_{i}=\ln \frac{\text { DensClas }}{\text { DensMap }}=\ln \frac{N p i x X i / N p i x N i}{\sum N p i x X i / \sum N p i x N i}
$$

$W_{\mathrm{i}}$ là trọng số của lớp i thuộc tác nhân gây trượt lở đang xem xét; DenClass là mật độ trượt lở đất của lớp i; DensMap là mật độ trượt lở trên toàn bộ khu vực nghiên cứu; NpixXi là số lượng điểm ảnh thuộc khoanh vi đại diện trượt lở xảy ra trong lớp i; NpixNi là số lượng điểm ảnh trong lớp i; $\Sigma$ npixXi là tổng số điểm ảnh trong khoanh vi đại diện trượt lở xảy ra ở toàn bộ khu vực nghiên cứu; $\Sigma$ npixNi là tổng số điểm trên toàn bộ khu vực nghiên cứu. 
Mỗi yếu tố ảnh hưởng tới quá trình trượt lở được thể hiện bằng một bản đồ trong GIS. Có thể nhận thấy mô hình giá trị thông tin được tính toán dựa trên tương quan thống kê của bản đồ hiện trạng trượt lở với các thuộc tính của bản đồ các yếu tố gây trượt khác nhau. Giá trị $\mathrm{W}_{\mathrm{i}}$ trong công thức trên chỉ tính toán cho các lớp của các yếu tố mà có xuất hiện trượt lở. Trong trường hợp trượt lở không xuất hiện trong một lớp nào của một bản đồ yếu tố gây trượt, giá trị $\mathrm{W}_{\mathrm{i}}$ sẽ được gán giá trị $=0$. Trong trường hợp một lớp nào đó của một yếu tố gây trượt không thấy xuất hiện trượt lở, thì trọng số của lớp đó sẽ không ảnh hưởng tới quá trình trượt lở trong khu vực nghiên cứu được thể hiện dưới dạng bản đồ.

Giá trị $\mathrm{W}_{\mathrm{i}}$ chỉ ra tầm quan trọng của từng loại yếu tố trong sự kiểm soát trượt lở. Nếu tổng trọng số là dương, đó là thuận lợi cho sự xuất hiện của lở đất, nếu nó là âm, thì ngược lại (van Westen và nnk., 2003). Chỉ số Wi càng cao thì mức độ thuận lợi đối với nguy cơ xảy ra trượt lở càng lớn.

Bảng 3: Kết quả tính toán giá trị $W_{i}$ của các lớp trong các yếu tố gây trượt lở đất

\begin{tabular}{|c|c|c|c|c|}
\hline Lớp & Tên lớp & $\begin{array}{c}\text { Phân bô lớp } \\
\text { (\%) }\end{array}$ & $\begin{array}{c}\text { Phân bô trượt } \\
\text { lở (\%) }\end{array}$ & $\mathbf{w}_{\mathbf{i}}$ \\
\hline \multicolumn{5}{|c|}{ Độ dốc () } \\
\hline 1 & $0-8^{0}$ & 15,07 & 13,14 & $-0,1370$ \\
\hline 2 & $8-15^{\circ}$ & 10,45 & 12,67 & 0,1926 \\
\hline 3 & $15-25^{\circ}$ & 30,73 & 35,18 & 0,1352 \\
\hline 4 & $25-35^{\circ}$ & 30,11 & 28,42 & $-0,0578$ \\
\hline 5 & $>35^{\circ}$ & 13,64 & 10,59 & $-0,2531$ \\
\hline \multicolumn{5}{|c|}{ Thạch học } \\
\hline 1 & Trầm tích bở rời đệ tứ & 1,37 & 0,3 & $-1,5188$ \\
\hline 2 & Đá trầm tích lục nguyên giàu alumosilicat & 33,31 & 36,79 & 0,0994 \\
\hline 3 & Đá lục nguyên giàu thạch anh & 11,63 & 11,72 & 0,0077 \\
\hline 4 & Đá xâm nhập mafic và siêu mafic & 5,84 & 5,05 & $-0,1453$ \\
\hline 5 & Đá xâm nhập axit-trung tính & 5,15 & 11 & 0,7589 \\
\hline 6 & Đá biến chất giàu alumosilicat & 40,16 & 29,71 & $-0,3014$ \\
\hline 7 & Đá biến chất giàu thạch anh & 2,56 & 5,43 & 0,7519 \\
\hline \multicolumn{5}{|c|}{ Thảm thực vật } \\
\hline 1 & Rừng trung bình & 30,71 & 34,16 & 0,1065 \\
\hline 2 & Rừng thưa & 17,07 & 12,03 & $-0,3499$ \\
\hline 3 & Cây bụi rải rác & 40,03 & 44,03 & 0,0952 \\
\hline 4 & Đất trống & 0,61 & 0 & 0 \\
\hline 5 & Đất nông nghiệp & 8,36 & 7,61 & $-0,0940$ \\
\hline 6 & Khu dân cư & 3,1 & 2,17 & $-0,3567$ \\
\hline 7 & Mặt nước & 0,12 & 0 & 0 \\
\hline \multicolumn{5}{|c|}{ Vỏ phong hoá } \\
\hline 1 & Sialit & 0,18 & 8 & 0 \\
\hline 2 & Sialit kiềm & 0,06 & 0 & 0 \\
\hline 3 & Sialit - Ferosialit & 22,58 & 15,86 & $-0,3533$ \\
\hline 4 & SiFerit - Ferosialit & 37,23 & 38,89 & 0,0436 \\
\hline 5 & Sialit - Ferosialit - Sialit kiềm & 4,07 & 7,36 & 0,5924 \\
\hline 6 & Sialit - Ferosialit - Sialit & 12,45 & 17,02 & 0,3127 \\
\hline 7 & Ferosiatlit & 10,48 & 6,1 & $-0,5412$ \\
\hline 8 & Alferit-Sialit & 6,28 & 13,5 & 0,7653 \\
\hline 9 & Alferit - Sialit kiềm & 4,35 & 1,04 & $-1,4310$ \\
\hline 10 & Alferit & 2,3 & 0,22 & $-2,3470$ \\
\hline
\end{tabular}




\begin{tabular}{|c|c|c|c|c|}
\hline \multicolumn{5}{|c|}{ Địa mạo } \\
\hline 1 & Sườn kiến tạo đổ lở >45ํ tuổi Đệ tứ không phân chia & 0,99 & 0,78 & $-0,2384$ \\
\hline 2 & Sườn bóc mòn kiến trúc dốc $20-30^{\circ}$ tuổi Đệ tứ không phân chia & 1,55 & 1,23 & $-0,2312$ \\
\hline 3 & $\begin{array}{l}\text { Bê mặt san băng bóc mòn không hoàn toàn cao } 1200 \text {-1400m tuôi } \\
\text { Miocen giữa }\end{array}$ & 1,05 & 2,67 & 0,9333 \\
\hline 4 & $\begin{array}{l}\text { Bề mặt sang băng bóc mòn không hoàn toàn cao 800-1000m tuối } \\
\text { Miocen muộn }\end{array}$ & 4,33 & 7,67 & 0,5717 \\
\hline 5 & Bề mặt pediment thung lũng cao 400-600m tuổi Pliocen sớm & 4,21 & 5,17 & 0,2054 \\
\hline 6 & Bề mặt pediment thung lũng cao 200-400m tuôi Plicocen muộn & 0,82 & 0,22 & $-1,3157$ \\
\hline 7 & Sườn bóc mòn tống hợp tuối Đệ tứ không phân chia & 27,24 & 29,54 & 0,0811 \\
\hline 8 & Sườn trọng lực tuối Đệ tứ không phân chia & 11,17 & 25,79 & 0,8368 \\
\hline 9 & Sườn xâm thực tuổi Đệ tứ không phân chia & 6,74 & 5,22 & $-0,2556$ \\
\hline 10 & Sườn xâm thực-rửa trôi bề mặt tuối Đệ tứ không phân chia & 11,51 & 3,26 & $-1,2615$ \\
\hline 11 & Sườn và bề mặt rửa trôi & 3,95 & 2,33 & $-0,5278$ \\
\hline 12 & Tập hợp các bề mặt vòm, đỉnh karst cao 600-800m & 6,18 & 2,07 & $-1,0938$ \\
\hline 13 & Vách và sườn hoà tan, rửa lũa, đố lở karst & 4,23 & 1,56 & $-0,9975$ \\
\hline 14 & Cánh đồng karst tích tụ các sản phấm aluvi-proluvi-deluvi & 1,14 & 0,44 & $-0,9520$ \\
\hline 15 & Phễu karst & 0,25 & 0,58 & 0,8416 \\
\hline 16 & Khe rãnh và đáy trũng xâm thực sông suối lộ đá gốc & 8,97 & 10,57 & 0,1641 \\
\hline 17 & Lòng sông và bãi bồi không phân chia & 3,27 & 0,42 & $-2,0523$ \\
\hline 18 & Thềm tích tụ sông bậc I & 0,33 & 0,11 & $-1,0986$ \\
\hline 19 & Thêm xâm thực-tích tụ bậc I & 0,44 & 0 & 0 \\
\hline 20 & Bề mạt đáy trũng giữa núi tích tụ hỗn hợp sông-lũ & 1,02 & 0 & 0 \\
\hline 21 & Bề mặt tích tụ hốn hợp sông-lũ & 0,11 & 0 & 0 \\
\hline 22 & Bề mặt tích tụ sườn tích-lũ tích & 0,5 & 0,38 & $-0,2744$ \\
\hline \multicolumn{5}{|c|}{ Lượng mưa (mm/năm) } \\
\hline 1 & 1600 & 4,29 & 1,18 & $-1,2908$ \\
\hline 2 & 1700 & 16,22 & 22,7 & 0,3361 \\
\hline 3 & 1800 & 53,82 & 56,1 & 0,0415 \\
\hline 4 & 1900 & 13,96 & 17,05 & 0,2000 \\
\hline 5 & 2000 & 11,71 & 2,96 & $-1,3753$ \\
\hline \multicolumn{5}{|c|}{ Khoảng cách tới đường giao thông (m) } \\
\hline 1 & $<50$ & 2,65 & 1,93 & $-0,3170$ \\
\hline 2 & $50-100$ & 2,59 & 2,17 & $-0,1769$ \\
\hline 3 & $>100$ & 94,76 & 95,9 & 0,0120 \\
\hline \multicolumn{5}{|c|}{ Cấp độ lệch } \\
\hline 1 & $0^{0}-36^{\circ}$ & 25,52 & 27,92 & 0,0899 \\
\hline 2 & $36^{0}-72^{\circ}$ & 21,28 & 22,55 & 0,0580 \\
\hline 3 & $72^{\circ}-108^{\circ}$ & 17,48 & 16,65 & $-0,0486$ \\
\hline 4 & $108^{\circ}-144^{\circ}$ & 13,21 & 9,82 & $-0,2966$ \\
\hline 5 & $144^{\circ}-180^{\circ}$ & 9,7 & 5,8 & $-0,5143$ \\
\hline \multicolumn{5}{|c|}{ Mật độ lineament $\left(\mathrm{km} / \mathrm{km}^{2}\right)$} \\
\hline 1 & $<0,5$ & 31,16 & 32,17 & 0,0319 \\
\hline 2 & $0,5-1$ & 20,84 & 21,5 & 0,312 \\
\hline 3 & $1-1,5$ & 24,47 & 24,76 & 0,0118 \\
\hline 4 & $1,5-2$ & 12,33 & 10,82 & $-0,1306$ \\
\hline 5 & $>2$ & 11,2 & 10,75 & $-0,0410$ \\
\hline \multicolumn{5}{|c|}{ Phân cắt sâu địa hình (m) } \\
\hline 1 & $<100$ & 4,48 & 0,67 & $-1,9001$ \\
\hline 2 & $100-200$ & 25,57 & 9,48 & $-0,9922$ \\
\hline 3 & $200-300$ & 33,04 & 31,83 & $-0,0373$ \\
\hline 4 & $300-400$ & 22,40 & 36,16 & 0,4789 \\
\hline 5 & $>400$ & 14,51 & 21,86 & 0,4098 \\
\hline \multicolumn{5}{|c|}{ Chia căt $\mathrm{ngang}\left(\mathrm{km} / \mathrm{km}^{2}\right)$} \\
\hline 1 & $0-0,5$ & 46,43 & 52,91 & 0,1306 \\
\hline 2 & $0,5-1,5$ & 34,75 & 33,41 & $-0,0393$ \\
\hline 3 & $1,5-2,5$ & 15,95 & 12,46 & $-0,2469$ \\
\hline 4 & $2,5-3$ & 2,02 & 1,05 & $-0,6543$ \\
\hline 5 & $>3$ & 0,86 & 0,16 & $-1,6818$ \\
\hline
\end{tabular}




\section{Bản đồ nguy cơ trượt lở đất}

Chỉ số nguy cơ trượt lở đất là một tập hợp liên tục các giá trị nhạy cảm mang tính định lượng. Chỉ số này được tính bằng tổng các giá trị $\mathrm{W}_{\mathrm{i}}$ :

Trong đó: LSI là chỉ số nhạy cảm trượt lở (Landslide Susceptibility Index)

$W_{i}$ là trọng số của lớp $i$ thuộc tác nhân gây trượt lở đang xem xét

$\mathrm{n}$ là số lượng các yếu tố gây trượt

$$
\text { LSI }=\sum_{i=1}^{n} W_{i}
$$

Dựa trên việc phân chia các nhóm giá trị LSI vào một khu vực có cùng nguy cơ. Chúng tôi chia thành 5 mức: rất thấp, thấp, trung bình, cao, rất cao. (Xem bảng 3 )

\section{Kiểm chứng}

Trong hầu hết các nghiên cứu về trượt lở, sự phân bố hiện trạng trượt lở trong các nhóm nguy cơ trượt lở khác nhau luôn được coi là yếu tố chìa khóa khi đánh giá mức độ chính xác của kết quả dự báo. Đường cong tỉ lệ dự đoán là một phương pháp kiểm định độ chính xác của mô hình dự đoán nguy cơ trượt lở thông qua các công cụ toán học và thống kê được nhiều tác giả sử dụng (Akgün và Turk, 2010) và được coi là phương pháp phổ biến nhất trong đánh giá tai biến trượt lở đất (Begueria, 2006). Theo đó bản đồ hiện trạng trượt lở sẽ được chồng chập với bản đồ chỉ số nguy trượt lở. Các giá trị phần trăm tích lũy của diện tích trượt lở (độ nhạy - sensitivity) và phần trăm tích lũy của diện tích LSI tương ứng (độ đặc hiệu - specificity) được tính toán bằng công cụ phân tích không gian và thống kê trong phần mềm ArcGIS 10.0. Diện tích tính được dưới đường cong (AUC-Area Under Curve) chính là độ chính xác của mô hình dự đoán. Trong nghiên cứu này giá trị $A \cup C=0,724$ nằm trong khoảng chấp nhận được (từ 0,5 đến 1). (Xem hinh 6)

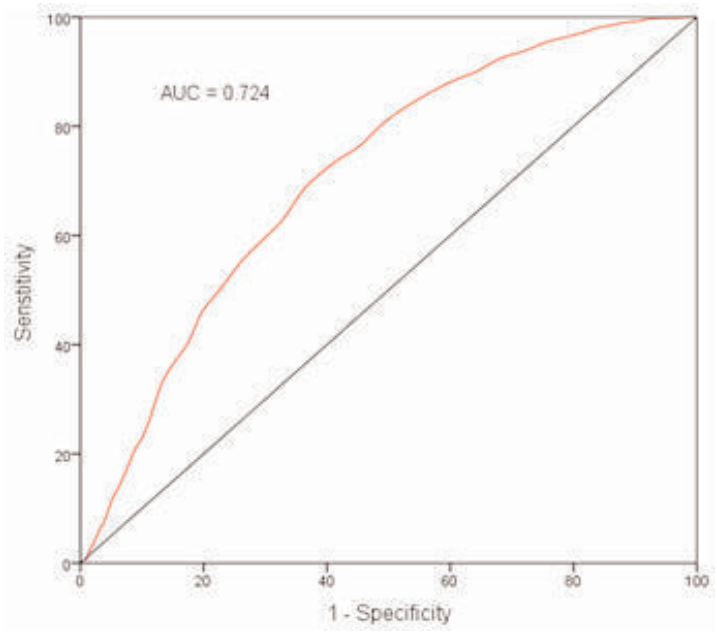

Hình 6: Biểu đồ diện tích dưới đường cong $A \cup C$

Bảng 4: Thống kê các vùng nguy cơ trượt lở

\begin{tabular}{|c|c|c|c|}
\hline \multirow{2}{*}{} & \multirow{2}{*}{ Chỉ số LSI } & \multicolumn{2}{|c|}{ Diện tích } \\
\cline { 3 - 4 } & & $\mathbf{( \mathbf { k m } ^ { 2 } )}$ & $\mathbf{( \% )}$ \\
\hline Rất thấp & $-12,42 \div-2,91$ & 1423 & 29,29 \\
\hline Thấp & $-2,91 \div-1,83$ & 1026 & 21,12 \\
\hline Trung bình & $-1,83 \div-0,54$ & 1498 & 30,83 \\
\hline Cao & $-0,54 \div 0,16$ & 544 & 11,20 \\
\hline Rất cao & $0,16 \div 2,58$ & 368 & 7,57 \\
\hline
\end{tabular}




\section{Kết quả và thảo luận}

Ảnh vệ tinh độ phân giải cao kết hợp với kỹ thuật chồng phủ lên DEM, và sử dụng phương pháp giải đoán bằng mắt hoàn toàn có thể thành lập bản đồ hiện trạng trượt lở một cách đầy đủ, chi tiết.

Mức độ ảnh hưởng đến nguy cơ trượt lở đất của yếu tố góc lệch giữa hướng cắm của đá với hướng đổ của địa hình phù hợp với các nhận định của các nhà địa mạo, địa chất. Điều này được biểu hiện qua giá trị $W_{i}$ giảm dần khi góc lệch tăng lên, có nghĩa là góc lệch giữa hướng cắm của đá mà gần trùng với hướng đổ địa hình thì nguy cơ trượt lở xảy ra cao nhất, ngược lại nếu góc lệch này tăng càng cao, thì khả năng cản trở quá trình trượt lở càng cao.

Diện tích khu vực có nguy cơ trượt lở rất cao chiếm $10,5 \%$ diện tích toàn tỉnh. Tập trung ở các khu vực có vỏ phong hóa chủ yếu được thành tạo từ các vật liệu bở dời nằm trên các sườn dốc từ $25-35^{\circ}$ có lớp phủ thực vật mỏng và dọc theo các tuyến đường, cũng như các khu vực có độ chênh cao địa hình tương đối lớn. Điều này cho thấy mức độ tác động của con người đến quá trình trượt lở diễn ra mạnh mẽ, phù hợp với các nhận định có được trong quá trình khảo sát thực địa.

Độ chính xác của mô hình nghiên cứu áp dụng cho khu vực nghiên cứu đã được kiểm chứng qua thông qua giá trị AUC là tương đối cao $(A \cup C=0,724)$. O

\section{Tài liệu tham khảo}

[1]. Aleotti, P., Chowdhury, R., 1999. Landslide hazard assessment: summary review and new perspectives. Bulletin of Engineering Geology and the Environment, 58: 21-44.

[2]. Akgun, A., Turk, N., 2010. Landslide susceptibility mapping for Ayvalik (Western
Turkey) and its vicinity by multicriteria decision analysis. Environmental Earth Sciences 61, 595-611.

[3]. Ayalew, L., Yamagishi, H. and Ugawa, N., 2004. Landslide susceptibility mapping using GISbased weigthed linear combination, the case in Tsugawa area of Agano River, Niigata Prefecture, Japan. Landslides, 1:1 73-81.

[4]. Dahal, R. K., Hasegawa, S., Nonomura, A., Yamanaka, M., Dhakal, S., Paudyal, P., 2008. Predictive modelling of rainfall-induced landslide hazard in the Lesser Himalaya of Nepal based on weights-of-evidence. Geomorphology 102 (2008) 496-510.

[5]. Schuster, R.L., 1996. Socioeconomic significance of landslides. In: Turner, A.K., Schuster, R.L. (eds.) Landslides, Investigation and Mitigation. Transportation Research Board Special Report 247. National Academy Press, WA, 12-35.

[6]. Van Westen, C.J., Rengers, N. and Soeters, R.(2003) Use of geomorphological information in indirect landslide susceptibility assessment. Natural Hazards, 30: 399-419.

[7]. Wieczorek, G.F., 1996. Landslide triggering mechanisms. In: Turner, A.K. and Schuster, R.L. (eds.) Landslides: Investigation and Mitigation. Washington, D.C., National Research Council, Transportation Research Board Special Report 247, 76-90.

[8]. Yin, K. L. and Yan, T. Z., 1988. Statistical prediction models for slope instability of metamorphosed rocks, In Bonnard, C. (Ed.), Landslides, Proceedings of the Fifth International Symposium on Landslides, 2, Balkema, Rotterdam, 1269-1272, 1988.O

(Xem tiếp trang 52) 